\title{
Examination of the Efficiency of Algorithms for Increasing the Reliability of Information on Criteria of Harness and the Cost of Processing Electronic Documents
}

\author{
Jumanov I.I., Karshiev Kh. B., Tishlikov S.A
}

\begin{abstract}
The task of analyzing the effectiveness of the functioning of electronic document management systems (EDMS) is formulated and the methodological basis for optimization is developed according to the criteria of reliability, complexity and cost of information processing. A technique for estimating the time of input, transmission, storage, processing, exchange of documents and increasing the reliability of information based on implemented and traditional approaches aimed at using statistical, logical, semantic and structural . technological relationships of document elements is proposed. Models and algorithms for optimizing the placement of electronic documents (ED) in databases and other information systems associated with the system have been developed. Methods are proposed to minimize the time of searching, processing, increasing the reliability of information and presenting the required document to the user. A computational scheme for solving the optimization problem based on the use of adaptive methods of stochastic random search, modeling by a truncated Markov chain and dynamic programming has been developed and implemented. The conditions for optimizing the values of the labor-intensiveness coefficients and the cost of information processing algorithms based on the application of linear constraints on their efficiency areas are studied. The experimental results of the gain coefficient in the reliability of the information obtained by the maximum rating score are obtained. The software package has been implemented and the values of the coefficient of efficiency of algorithms for increasing the reliability of information based on the use of adaptive random search, segmentation, semantic redundancy and lexicological synthesis of the structure of electronic documents have been analyzed.
\end{abstract}

KEY WORDS: efficiency, electronic document management system, the complexity and cost of information processing, the reliability of information, optimization, optimization strategy, stochastic model.

\section{INTRODUCTION}

The functioning of electronic document management agencies, information resource and monitoring systems is associated with the input, transmission, formation, storage, editing, reliability control of information, the presentation of organizational and administrative documents to users whose software tools are integrated with other information systems $[1,2]$. It is required that the results of these functions ensure the integrity, security, completeness, relevance of documents, as well as the reliability of the information at all stages of input, transmission, search, processing of a larger number of electronic documents (ED) [3]. In electronic document management systems (EMDS), tasks are also solved to optimize information processing, which are aimed at finding parameters in accordance with the criteria for minimizing the volume of documents occupied in databases, the time it takes to obtain the required ED from the database, and other information systems.

The quality of EDMS depends on the results of the following processes [4-6]:

- input information using a human operator, technical means of scanning and recognition;

- information transfer on local, corporate, global, satellite networks;

- storage of operational, medium-term, long-term information, the formation of a database, knowledge base, as well as the placement of document flows in other information systems;

- statistical, dynamic, intellectual analysis and information processing;

- increase the reliability of information, service, presentation of services to the user with the results.

In this work, the methodological foundations of a multi-criteria analysis of the quality of functioning of EDMS and the effectiveness of the implemented methods and algorithms for increasing the reliability of information are developed.

\section{THE BASIC PRINCIPLES OF THE ANALYSIS OF THE QUALITY OF FUNCTIONING OF EDMS.}

Criteria of the effectiveness of the functioning of EDMS are examined in the form of time and cost indicators, the results of which are evaluated from the stage of document input to the provision of services to the user, taking into account the contribution of each instrument to increase the reliability of document information[7].

Optimization of the accuracy of processing information of documents begins with solving the problem of 
placing streams of ED in a database, minimizing the time they are presented to the user from the database and from other information systems, minimizing the total amount of memory occupied by system documents. In this regard, the following optimization principles are observed [8]:

- The first principle is aimed at minimizing the time of obtaining the required document by the user, which is the sum of the time the request was sent, the document is searched, the information is processed, and the time the ED are presented to the user. The objective optimization function depends on the methods of organization and placement of ED in databases in other information systems;

- the second principle, aimed at minimizing the time and cost of exchanging documents by the user and the database system, as well as by the user and other information systems;

- the third principle, aimed at minimizing the memory of stored ED in the database of the system in order to reduce non-periodic costs of storage, updating, making changes to documents located in all storages and in other information systems;

- the fourth principle, aimed at minimizing the cost of obtaining the desired document by the user, transmitting information, increasing the reliability of information and correcting the contents of the document.

\section{OPTIMIZATION OF THE PLACEMENT OF DOCUMENTS IN THE DATABASE}

$$
\left(\left(x_{i} \geq x_{j}+l_{j}\right) \vee\left(x_{j} \geq x_{i}+l_{i}\right) \vee\left(y_{i} \geq y_{j}+w_{j}\right) \vee\left(y_{j} \geq y_{i}+w_{i}\right)\right)
$$

where $i, j=1,2, \ldots, m, i \neq j$;

- no object crosses the borders of the strip i.e $\left(x_{i} \geq 0\right) \wedge\left(y_{i} \geq 0\right) \wedge\left(y_{i}+w_{i} \leq W\right)$ for $i=1,2, \ldots, m$.

The geometric meaning of the variables $W$ is presented in [2].

It is required to place a set of rectangular objects on an infinite strip so that the part of the strip occupied by them is minimal in length. Therefore, there is a set $\left(x_{i}, y_{i}\right)$ such that

$$
L=\max \left(x_{i}+l_{i}\right) \rightarrow \min ,
$$

where $L\left(l_{i}, w_{i}\right),\left(x_{i}, y_{i}\right), i=1,2, \ldots, m$. infinite strip with a width $W$ for placement, $m$ round objects whose radii are known as $r_{i}$. The optimization problem is solved under the following conditions:

- $\left(x_{i}, y_{i}\right)$ - coordinates of the center of circle $i$ on the strip; each other i.e

- when placed on a strip, no two items intersect with

The principle of cutting round objects. In this version of the solution, the problem of placing ED in databases for which the required memory is represented on an

$$
\left(x_{i}-x_{j}\right)^{2}+\left(y_{i}-y_{j}\right)^{2} \geq\left(r_{i}+r_{j}\right)^{2} \text {; }
$$

- no object crosses the borders of the strip i.e.

$$
\left(x_{i}-r_{j} \geq 0\right) \wedge\left(y_{i}-r_{i} \geq 0\right) \wedge\left(y_{i}+r_{i} \leq W\right) \text {. }
$$

Therefore, it is required to place a set of round objects on an infinite strip so that the part of the strip occupied by them is minimal in length, and the placement should be as dense as possible. The length of the strip occupied by the placement of objects is optimized.

\section{MINIMIZING THE TIME (COST) OF SUBMITTING ED TO THE USER FROM THE DATABASE AND FROM OTHER IS}

The objective function $\mathrm{F}_{1}$ is defined as

$$
F_{1}=t^{\prime}+t^{\prime \prime} \rightarrow \min ,
$$

where $t^{\prime}$ - the average time the user receives ED from the database; 

other IS.

$$
t^{\prime \prime} \text { - the average time the user receives ED from }
$$

Positive results of solving problems are achieved depending on the methods used to place data in the database of the system and in other information systems, search, and also to increase the reliability of information [11, 12].

The time (cost) of information processing in the system is optimized by functionality

$$
F_{2}=\sum_{i=1}^{N} \sum_{j=1}^{n_{i}} W_{i j}^{\prime}+\sum_{i=1}^{M} \sum_{j=1}^{m_{i}} W_{i j}^{\prime \prime} \rightarrow \min ,
$$

where $n_{i}$ - the number of ED stored in database $H_{i}$;

$m_{i}$ - the number of ED stored in other IS $I_{i}$;

$N$ - the number of database systems;

$W_{i j}^{\prime}$ - the time (cost) of providing services to the user according to document $d_{j}$ from database $H_{i}$;

$W_{i j}^{\prime \prime}$ - time (cost) of the provision of services for document $d_{j}$ from other information systems $I_{i}$.

ED are presented in the form of an attached file, a set of files of arbitrary size, and each of them can have a certain number of copies in various repositories.

\section{THE TASK OF OPTIMIZING THE SEARCH FOR THE REQUIRED ED}

The optimization of the problem is connected with the routing method, in which the optimal solution is found taking into account its large size and is a laborious task. To optimize the search route of objects, a special type of matrix is used. In it, search objects form rows, and the columns display a list of rules received along the route [13].

At the position $(x, i)$ of the matrix is 1 in the case when the object x occupies the $i$-th place in the route. In the case of $n$ search objects, we are faced with $\frac{n !}{2 n}$ different rules retrieved in the search route and it is required to find the shortest among them. In this regard, in contrast to traditional approaches aimed at optimizing the identification of the route of search objects, an approach is proposed related to the use of neural networks (NN), in particular the Hopfield network. In this case, a matrix of neurons of size $n \times n$ etworks is compiled, which interact in rows and columns.

In it, each neuron is denoted by two indices $x$ and $i$, moreover, $x$ reflects the object, and the $i$-th position in the search route, i.e. $z_{x i}$ - the output of a neuron in which object $x$ is located at the $i$-th position of the route. However, the Hopfield $\mathrm{NN}$ is distinguished by computational complexity ( $n^{4}$, where $n$ is the dimension of the problem) and the need to apply the mechanism of multi-iterative selection of variables for the neuron activation function.

To simplify the calculations associated with the search for an object, a recurrent $\mathrm{NN}$ is used in the implementation,
$M$ - the number of other IS connected to EMDS;

which reduces the complexity of the routing algorithm from $O\left(n^{4}\right)$ to $O\left(n^{2}\right)$.

Further, the search mechanism is modified using the grafted model, which consists of edges connecting the nearest vertices. New vertices are selected not with equal probability, but with a probability depending on the distance from the current one. The larger it is, the smaller the value of this probability will be. The modified search algorithm is characterized by the following features [14]:

- the agent launched to go along the search route saves the previous object search route;

- if the agent was already at this peak, then he himself is destroyed;

- the number of user requests is selected based on the condition

$$
H \cdot N \geq|G|,
$$

where $H$ is the size of the ED (number of elements); $N$ is the size of the desired document concept (the number of elements in the concept); $G$ - database capacity (number of ED).

\section{MINIMIZATION OF NON-PERIODIC TIME AND COST COSTS}

The minimization of non-periodic time and cost costs for storage, updating, changes to the entire information storage is set by the following objective function $\mathrm{F}_{3}$

$$
F_{3}=\sum_{i=1}^{N} \sum_{j=1}^{n_{i}} v_{i j} \rightarrow \min ,
$$

where $v_{i j}$ - the amount of information of ED $d_{j}$ in the database memory $H_{i}$.

The integral cost criterion $S_{\text {int }}$ is defined as

$$
S_{\text {int }}=\left(S_{c s}+S_{\text {cos }}+S_{c o d s}\right) \rightarrow \min ,
$$

where $S_{c s}$ - the cost of storing ED in the database system;

$S_{\text {cos }}$ - the cost of obtaining ED by the user from other IS;

$S_{\text {cods }}$ - the cost of obtaining ED by the user from the database system.

\section{MINIMIZING THE TIME FOR THE USER TO RECEIVE ED FROM OTHER IS}

The average time $\tau_{i}$ of receipt of ED $d_{j}$ at the request of the user is limited by the permissible time $T_{i}{ }^{\prime}$ i.e.

$$
\tau_{i} \leq T_{i}^{\prime}
$$

The frequency of requests to other IS $I_{i}$ set in the form

$$
Q_{i}^{\prime}=\sum_{i=1}^{N} \sum_{j=1}^{m_{i}} \eta_{i j}^{\prime} y_{i j}
$$


where $\eta_{i j}^{\prime}$ - the frequency of circulation to another information system $I_{i}$;

$y_{i j}$ - indicator showing the presence of the required ED in other IS $I_{i}$

$$
y_{i j}=\left\{\begin{array}{c}
1, \text { is avaiable if } \quad d_{j} \in I_{i} \\
0, \text { not is aviable if } d_{j} \notin I_{i} .
\end{array}\right.
$$

The size of memory required for storing $\mathrm{ED}$ in the database is limited in the form

$$
\sum_{i=1}^{N} \sum_{j=1}^{n_{i}} x_{i j} v_{i j} \leq \sum_{i=1}^{n} O_{i},
$$

where $x_{i j}$ the number of $d_{j}$ in $H_{i}$;

$O_{i}$ - the amount of memory allowed for the placement of ED in the database $H_{i}$.

The average time the document is presented to the user by the system is specified as

$$
\tau_{i}=\frac{1}{Q_{i}^{\prime}} \sum_{i=1}^{N} \sum_{j=1}^{m} \tau_{i j} \eta_{i j}^{\prime} y_{i j},
$$

where $\tau_{i j}=\frac{v_{i j}^{\prime}}{R_{i}^{\prime}}$ is the time for the transfer of ED $d_{j}$ with the amount of information $v_{i j}^{\prime}$ from other IS $I_{i}$;

$R_{i}^{\prime}$ - the bandwidth of the channels for processing information of EDMS.

Substituting (6) into (8) we obtain

$$
\frac{1}{Q_{i}^{\prime}} \sum_{i=1}^{N} \sum_{j=1}^{m} \tau_{i j} \eta_{i j}^{\prime} y_{i j} \leq T_{i}^{\prime}
$$
in the form

The cost of storing ED in the system database is set

$$
\begin{aligned}
S_{c s}= & \sum_{i=1}^{N} \sum_{j=1}^{n_{i}} s_{i}^{c s} x_{i j}\left(\sum_{k=1}^{n_{i}} v_{i j k}^{\prime}+\sum_{k=1}^{n_{i}} v_{i j k}^{\prime \prime}\right), \\
& s_{i}^{c s}=\frac{W_{i}^{c s}}{V_{i}^{c s}}-\text { the cost of storing a unit of }
\end{aligned}
$$

information in the database $H_{i}$;

$W_{i}^{c s}$ - the cost of forming the database $H_{i}$;

$$
W_{i}^{c s}=W_{i}^{r p e}+W_{i}^{c s e},
$$

$W_{i}^{\text {rpe }}$ - rental price of equipment;

$W_{i}^{r p e}=W_{i}^{c e} r d, W_{i}^{c e}$ - the cost of equipment; $r$ - is the depreciation coefficient; $d$ - discount rates; $W_{i}^{c s e}$ - the cost of servicing equipment;

$$
W_{i}^{c s}=W_{i}^{o s}+W_{i}^{t p}+W_{i}^{l p}+W_{i}^{r},
$$

$W_{i}^{o s}$ - operator's salary; $W_{i}^{t p}$ - cost of technical support; $W_{i}^{l p}$ - the cost of licensing policy; $W_{i}^{r}$ - rental price; $V_{i}^{c s}$ - the volume of the database storage $H_{i}$.

The cost of submitting ED to the user from the $H_{i}$ database is set as

$$
S_{\mathrm{cos}}=\sum_{i=1}^{N}\left(\frac{1}{Q_{i}^{\prime}} \sum_{i=1}^{n_{i}} s_{i}^{\mathrm{cos}} \tau_{i j} \eta_{i j}^{\prime} x_{i j}\right),
$$

where $S_{i}^{\mathrm{cos}}$ is the cost of obtaining a unit of information from the database $H_{i}$;

$$
\begin{aligned}
s_{i}^{\cos } & =\left(\frac{W_{i}^{\cos }}{V_{i}^{\cos }}\right) R_{i} \text { and } W_{i}^{\cos }=W_{i}^{r p e}+W_{i}^{m} ; \\
& W_{i}^{m} \text { - the tariff cost of obtaining information from }
\end{aligned}
$$
the database $H_{i}$;

$V_{i}^{\text {cos }}$ - the amount of information transmitted from the database $H_{i}$;

The cost of submitting ED to the user from other information systems is set as

$$
S_{\text {cod }}=\sum_{i=1}^{N}\left(\frac{1}{Q_{i}^{\prime}} \sum_{j=1}^{m_{i}} s_{i}^{c o d} \tau_{i j} \eta_{i j}^{\prime} x_{i j}\right),
$$

where $S_{i}^{c o d}$ - the cost of obtaining a unit of information from other IS $I_{i}$;

$$
\begin{aligned}
& S_{i}^{c o d}=\left(\frac{W_{i}^{c o d}}{V_{i}^{c o d}}\right) R_{i} \text { and } \\
& W_{i}^{c o d}=W_{i}^{r p e}+W_{i}^{m} .
\end{aligned}
$$

The total cost of optimizing the algorithm for increasing the reliability of information at all stages of processing a document is set in the form

$$
S_{\text {sum }}=\lambda_{i}\left(S_{c s}+S_{\text {cos }}+S_{c o d}\right),
$$

where $\lambda_{i}$ - the gain coefficient in the reliability of the information.

Optimization of the reliability of information in the collection of documents is set by the functional 


$$
\begin{array}{r}
S_{o p t}=\lambda_{1} \sum_{i=1}^{N} \sum_{j=1}^{n_{i}} s_{i}^{c s} x_{i j}\left(\sum_{k=1}^{n_{i}} v_{i j k}^{\prime}+\sum_{k=1}^{n_{i}} \nu_{i j k}^{\prime \prime}\right) \\
+\lambda_{2} \sum_{i=1}^{N}\left(\frac{1}{Q_{i}^{\prime}} \sum_{i=1}^{n_{i}} s_{i}^{\cos } \tau_{i j} \eta_{i j}^{\prime} x_{i j}\right)+ \\
+\lambda_{3} \sum_{i=1}^{N}\left(\frac{1}{Q_{i}^{\prime}} \sum_{j=1}^{m_{i}} s_{i}^{c o d} \tau_{i j} \eta_{i j}^{\prime} x_{i j}\right) \rightarrow \min .
\end{array}
$$

The computational scheme the problem is based on the use of dynamic programming [8].

The win coefficient in the cost of processing information is set in the form

$$
K_{s}=1-\frac{S_{o p t}}{S_{\text {sum }}} .
$$

The complexity of each operation ti associated with document processing is determined by dividing the total amount of information Qi by the established norm $\mathrm{Ni}$ (standard amount of information), as

$$
t_{i}=\frac{Q_{i}}{N_{i}}
$$

The total complexity performing $n$ operations is determined as

The win coefficient in the complexity of information processing is determined, similarly, by the technique (14)

$$
K_{T}=1-\frac{T_{o p t}}{T_{\text {sum }}}
$$

where $T_{\text {onm }}$ - is the optimal complexity of information processing

Multicriteria optimization of the reliability of information on the functional (14) is performed under the following restrictions [15]

$$
T \leq K^{*} ; \quad S \leq Q^{*},
$$

where $T$ and $S$ - the criteria for the complexity and cost of processing information;

$Q^{*}$ and $K *$ - restrictions on the values of the criteria $T$ and $S$.

To analyze the effectiveness of the algorithms, the range of admissible values of the criteria $T$ and $S$ is narrowed by maintaining the following restrictions:

$$
\begin{gathered}
T \leq \lambda_{1}+\lambda_{2} d \text { or } T \leq a \cdot K^{*}+b ; \\
S \leq \lambda_{1}+\lambda_{2} d \text { or } S \leq a \cdot Q^{*}+b ; \\
K^{*}=Q^{*}=d,
\end{gathered}
$$

where $a=\lambda_{2}$ is the upper and $b=\lambda_{1}$ is the lower bounds of the criteria;

$d$ - the geometric distance between the points of the boundaries of the efficiency of the algorithm.

In solving this problem, the values of $a$ and $b$ are selected and the effective optimization area is adjusted. For the analysis of the complexity factor of information processing, the following values of variables are set: the total amount of information in one document is $8 \cdot 10^{6}$ bits; information processing time $0.008 \mathrm{sec}$, and the entire collection of 100 documents $0.8 \mathrm{sec}$.

Optimization options are considered, in which a linear restriction is placed on the criteria together with typical limit restrictions. This approach made it possible to set the level of compensation between conflicting factors and to achieve a significant narrowing of the range of feasible solutions.

The optimal points for the coefficients $K_{s}$ and $K_{T}$ in the region of admissible values are obtained for the greedy search algorithm for the global extremum with linear constraint. It is established that the implemented algorithm ensures the achievement of the required value of the efficiency functional at 1600 iterations in comparison with the search algorithm with a complete enumeration of all kinds of options that runs at 65536 iterations. When segmentation and parallel computing mechanisms are applied, the advantages of glg fithms for increasing the reliability of ED processing in@rease 10-15 times.

\section{THE EFFECTIVENESS OF THE SOFTWARE PACKAGE TO INCREASE THE RELIABILITY OF INFORMATION}

A software package was developed and implemented to increase the reliability of information, the effectiveness of which is determined by the criterion $S_{i}$ - the cost of detecting and correcting errors by the $i$-th algorithm. In this case, the $S_{i}$ criterion is studied taking into account the criterion of the $T$-averaged value of the complexity, which are associated with increasing the reliability of a collection of 100 documents at all stages of information processing in the form [15]

$$
S_{i}=\lim _{T \rightarrow \infty} T^{-1} \sum_{i=1}^{100} T_{i} \lambda_{i} \rightarrow \min .
$$

Achieved high value, which should be close to or equal to

$$
d(S)=\sup _{\lambda_{i} \in S}\left(T_{i} \lambda_{i}\right)
$$

In many cases, the gradient method is used to optimize the function $d(S)$, the implementation of which is due to the following disadvantages: computational difficulties; the lack of the possibility of an explicit analytical representation of the function: the impossibility of obtaining its derivative characteristics. 
An adaptive functional optimization strategy is proposed in which, instead of the exact value of the function gradient, its estimates are used. In the developed complex, a stochastic search algorithm is synthesized from a partially observable Markov chain. The advantage of this algorithm is that it is executed under conditions of minimal a priori information. The following important points of the research results were established:

- adaptive optimization allows you to get a stable value of the strategy (point) on the set $C$ up to the third sign; - the probability of choosing the values of the parameter $C_{\text {adap }}$ is estimated within the framework of the best and worst strategies $C_{\max }$ and $C_{\text {min }}$, which, with adaptive search optimization, turned out to be an internal point in the set of values of $C$;
- the spread between the values of the best and worst strategies obtained on the basis of a random search algorithm with enumeration of all options turned out to be quite large;

- the objective optimization function becomes sensitive when tuning the variables, which is reflected by lower values of the efficiency coefficient of the algorithm;

- it was proved that the complexity of processing the information of an algorithm with adaptive search for a global extremum of a functional based on a stochastic model with a partial Markov chain is an order of magnitude less than the complexity of an algorithm with a search mechanism with random enumeration of all kinds of options, which also gives less accurate results.

Table 1 shows the results of the rating achieved at the output of the complex, the graphs of which reflect the effectiveness of algorithms to increase the reliability of information (AIRI), and the traditional technology of visual information control (TVIC).

The results of the task of optimizing the reliability of information in ED

\begin{tabular}{|c|c|c|c|c|c|}
\hline \multirow{2}{*}{ Strategy } & \multirow{2}{*}{ Rating score } & \multicolumn{2}{|c|}{ Rating win } & \multirow{2}{*}{ Performance ratio } & \multirow{2}{*}{ Loss ratio } \\
\cline { 3 - 5 } & \multirow{2}{*}{ AIRI in $\%$} & TVIC in $\%$ & & 0,322 \\
\hline$C_{\text {adap }}$ & 37,76 & 67,49 & 32,51 & 0,94 & 0,539 \\
\hline$C_{\max }$ & 42,09 & 68,75 & 31,25 & 0,96 & 0,315 \\
\hline$C_{\min }$ & 25,40 & 48,15 & 51,85 & 0,68 & \multirow{2}{*}{} \\
\hline
\end{tabular}

\section{CONCLUSION}

The effectiveness of the software package to increase the reliability of information is studied on examples of the EMDS of a medical institution, higher educational institution, machine-building enterprise of the Samarkand region of the Republic of Uzbekistan. The values of the coefficients of gain in the reliability, complexity and cost of processing information using various methods are analyzed. Thanks to the use of the complex, the following results are achieved:

- the complexity and cost of processing a collection of 100 documents related to the implementation of the function of monitoring the implementation of organizational and administrative documents is reduced from 2.4 hours to 1.1 hours compared to the use of traditional technology for visual error correction;

- documents at the request of the user are submitted 2-3 times faster;

- the coefficients of the complexity and cost of processing information are reduced 5-7 times;

- in conditions when algorithms are used to increase the reliability of information based on the use of semantic redundancy and lexicological synthesis of the structure of ED, then the values of the labor-intensiveness coefficients and the cost of processing information are reduced by an average of $2-3$ times, and the reliability of the information is increased to two orders of magnitude.

\section{REFERENCES}

[1] Бессонов, С. В. Оптимизация электронного документооборота в корпоративных системах: дис. канд. экон. наук. / С. В. Бессонов. М., 200Г. - Г87 c.

[2] Гудов, А. М. Об одной модели оптимизации документопотоков, реализуемой при создании системы электронного документооборота Вычислительные технологии. - 2006. - Т. ГГ. спец. вып. - С. 53 - 65.

[3] Коновалов М.Г. Методы адаптивной обработки информации и их приложения. - М.: ИПИ РАН, 2007. 212 с.

[4] Архипова Н.И., Кульба В.В., Косяченко С.А., Чанхиева Ф.Ю Исследование систем управления. - М.: ПРИОР, 2002. - 132 с.

[5] Белоногов Г.Г., Калинин Ю.П., Хорошилов А.А. Теория и практика построения систем автоматической обработки текстовой информации - М.: Русский мир, 2004. - 248 с.

[6] Белоногов Г.Г., Зеленков Ю.Г. Алгоритм автоматического обнаружения орфографических ошибок в текстах // М.: ВИНИТИ. - Москва, 1986. - 15 с.

[7] Келдыш Н. В. Методические основы автоматизированного решения задач ведомственного электронного документооборота. // Научно-метод. сборник № 56. / ВА МО. - М., 2009. - С.110-117 Инв. № 58592.

[8] Жуманов И.И. Разработка теории, исследование, практическое применение методов контроля и формирования информации со статистической избыточностью. - докт. дисс., Ташкент, УзНПО «Кибернетика». - 1983.

[9] Беллман, Р. Прикладные задачи динамического программирования, М.: Наука: Глав. ред. физ.-мат. лит., Г965. $460 \mathrm{c}$.

[10] Жуманов И.И., Ахатов А.Р. Алгоритм контроля качества текстов в системах электронного документооборота // Журнал «Вестник ТУИТ». - Ташкент, 2007. - №2. - с. 68-72.

[11] Жуманов И.И., Ахатов А.Р. Повышение надежности программного обеспечения проблемных задач в системах электронного документооборота // Материалы респ. науч. конф. «Современное состояние и пути развития информационных технологий», НТЦ «СИТ». - Ташкент, 2006. - с. 164-167.

[12] Жуманов И.И., Ахатов А.Р. Оценка эффективности программного комплекса контроля достоверности текстовой информации систем электронного документооборота // НТЖ «Химическая технология. Контроль и управление» - Ташкент, 2009. - № 2, с. 46-52. 
[13] Jumanov I.I., Akhatov A.R. Fuzzy Semantic Hypernet for Information Authenticity Controlling in Electronic Document Circulation Systems // 4-th International Conference on Application of Information and Communication Technologies, 12-14 october 2010, Section 2, IEEE. Tashkent, 2010. - p.21-25.

[14] Jumanov I.I., Akhatov A.R., Tursinxanov N.M. Methods and Algorithms of Input Information Protection in Electronic Document Processing Systems//2nd IEEE/IFIP International Conference in Central Asia on Internet ICI-2006, September 19-21, International Hotel Tashkent, Uzbekistan.

[15] Jumanov I.I., A.R.Akhatov, Djumanov O.I. An Effective Quality Control of Textual Information on the Basis of Statistical Redundancy in Distributed Mobile IT Systems and e-Applications //3-d International Conference in Central Asia on Internet, IEEE Catalog Number: 07EX1695C, ISBN: 1-4244-1007-X, Library of Congress: 2007920881. - Tashkent, 2007. 